Article

\title{
Coumarin-Containing Light-Responsive Carboxymethyl Chitosan Micelles as Nanocarriers for Controlled Release of Pesticide
}

\author{
Song Feng, Junqin Wang, Lihua Zhang *, Qin Chen, Wang Yue, Ni Ke and Haibo Xie * \\ Department of Polymer Materials and Engineering, College of Materials and Metallurgy, Guizhou University, \\ Guiyang 550025, China; fszxy159@163.com (S.F.); Wjq010405@163.com (J.W.); qchen6@gzu.edu.cn (Q.C.); \\ wangy6186enoch@163.com (W.Y.); NIKO.KN@139.com (N.K.) \\ * Correspondence: lhzhang5@gzu.edu.cn (L.Z.); hbxie@gzu.edu.cn (H.X.)
}

Received: 26 August 2020; Accepted: 29 September 2020; Published: 1 October 2020

\begin{abstract}
Currently, controlled release formulations (CRFs) of pesticides in response to biotic and/or abiotic stimuli have shown great potential for providing "on-demand" smart release of loaded active ingredients. In this study, amphiphilic biopolymers were prepared by introducing hydrophobic (7-diethylaminocoumarin-4-yl)methyl succinate (DEACMS) onto the main chain of hydrophilic carboxymethylchitosan (CMCS) via the formation of amide bonds which were able to self-assemble into spherical micelles in aqueous media and were utilized as light-responsive nanocarriers for the controlled release of pesticides. FTIR and NMR characterizations confirmed the successful synthesis of the CMCS-DEACMS conjugate. The critical micelle concentration (CMC) decreased with the increase in the substitution of DEACMS on CMCS, which ranged from 0.013 to $0.042 \mathrm{mg} / \mathrm{mL}$. Upon irradiation under simulated sunlight, the hydrodynamic diameter, morphology, photophysical properties and photolysis were researched by means of dynamic light scattering (DLS), transmission electron microscopy (TEM), UV-vis absorption spectroscopy and fluorescence spectroscopy. Moreover, 2,4-dichlorophenoxyacetic acid (2,4-D) was used as a model pesticide and encapsulated into the CMCS-DEACMS micelles. In these micelle formulations, the release of 2,4-D was promoted upon simulated sunlight irradiation, during which the coumarin moieties were cleaved from the CMCS backbone, resulting in a shift of the hydrophilic-hydrophobic balance and destabilization of the micelles. Additionally, bioassay studies suggested that this 2,4-D contained which micelles showed good bioactivity on the target plant without harming the nontarget plant. Thereby, the light-responsive CMCS-DEACMS micelles bearing photocleavable coumarin moieties provide a smart delivery platform for agrochemicals.
\end{abstract}

Keywords: carboxymethyl chitosan micelles; light-responsive; coumarin; 2,4-D; controlled release; pesticide

\section{Introduction}

The extensive utilization of pesticides in controlling weeds, pests and fungi greatly contributes to ensuring global agricultural productivity [1-3]. Nonetheless, excessive and repetitive use of pesticides has led to a series of adverse effects on environmental quality, safety of agricultural products and human health [4]. Controlled delivery technology has proven its potential for sustainable use of pesticides in agriculture [5-7]. The advantages of controlled release formulations (CRFs) of pesticides over conventional formulations include (i) reducing losses induced by evaporation and leaching [8,9], (ii) prolonging effective lifetime [10], (iii) protecting the active ingredients against environmental degradation by photo, heat, humidity and microorganisms [11-13], (iv) minimizing residues in 
the environment, agricultural products and food chain [14] and (v) reducing toxicity for nontarget organisms including humans [15]. Therefore, much academic and industrial effort has been devoted to the improvement of CRFs of pesticides that ensure the agricultural yields through an environmentally friendly approach $[3,16,17]$.

Stimuli-responsive CRFs provide advanced and smart controlled release of pesticides, where the CRFs present responses to small external stimuli, resulting in changes in their chemicalor physical properties favoring the "on-demand" release of loaded pesticides [18]. Until now, several kinds of stimuli responsive CRFs have been fabricated using abiotic or biotic stimuli, such as enzymes [13], redox [19], $\mathrm{pH}$ [20], temperature [21] and light [22]. Compared with other stimuli, light as an external trigger for pesticide release has received a lot of attention, since it is a clean and remote stimulus that can be spatially and temporally controlled by tuning the intensity, wavelength and site of irradiation [23,24]. Light-controlled CRFs have strong potential applications in agriculture, able to take advantage of the abundant natural sunlight radiation in open fields, and even for greenhouses with simulated sunlight or UV light equipment [18]. Several light-responsive groups have been developed for this purpose, including coumarin [14], azobenzene [1], 2-nitrobenzyl [22] and spiropyran [25]. Among these light triggers, the coumarin-based platform is notably attractive because of the efficient photorelease ability and strong fluorescence property [26-28]. For example, Atta et al. reported a UV-light-responsive coumarin polymer for controlled release of pesticide 2,4-dichlorophenoxyacetic acid (2,4-D) [14]. Another distinct advantage of coumarin derivatives is the tunability of absorption wavelength by molecular design ( $\lambda_{\max }$ from $310 \mathrm{~nm}$ to $490 \mathrm{~nm}$ ), thus providing broader compatibility with light wavelength $[26,29]$. Reports have shown that the electron donating diethylamino substituents at the 7-position allows photochemical activity in the visible region, further allowing cleavage of the coumarin moieties from the polyphosphazene backbone upon visible light irradiation [30]. Xu et al. also reported a propesticide with 7-diethylamino substituted coumarin as a photocage for the release of insecticidal ingredients upon blue light or sunlight [31]. However, the current coumarin-based small molecule propesticide has certain obvious drawbacks such as its fast release rate and the need for organic solvents (i.e., methanol). Polymeric encapsulation seems to be a better choice in terms of prolonged and regulated release profile, eco-friendly aqueous media and multiple forms (i.e., capsules, micelles, microspheres and hydrogels) [10,22,32-35].

On the other hand, compared with synthetic polymers, the application of naturally occurring biopolymers (i.e., chitosan, cellulose and starch) as pesticide nanocarriers has a brighter future because of the desirable biodegradability, biocompatibility and adjustable physicochemical properties [33]. Typically, chitosan is among the most valuable biopolymers for the delivery of pesticides owing to its inherent antibacterial and antifungal activities $[15,36]$. It can even stimulate the innate immune systems of plants and improve resistance against disease and insects [37]. Chitosan molecules with enormous hydroxyls and amino groups can be readily modified for encapsulation and controlled release of agrochemicals, including herbicides, insecticides, plant growth regulators and fertilizers $[38,39]$.

Thus, the present study was carried out aiming to develop light-responsive CRFs based on chitosan micelles for the controlled release of pesticides. This amphiphilic chitosan derivative was prepared by covalently conjugating hydrophobic light-responsive (7-diethylaminocoumarin-4-yl)methyl succinate (DEACMS) onto the main chain of hydrophilic carboxymethyl chitosan (CMCS) via formation of an amide bond. The self-assembled light-responsive micelles were utilized as nanocarriers for the controlled release of 2,4-D, a phenoxyacetic acid herbicide. We chose 2,4-D as the model pesticide because of its global use but potential risks to human health, and it has been identified as a class 2B carcinogen by the International Agency for Research on Cancer (IARC) [40]. The morphology, hydrodynamic diameter, photophysical properties and light-controlled release behavior of CMCS-DEACMS micelles were investigated upon simulated sunlight irradiation. Finally, the bioactivity of 2,4-D-contained micelles against one dicot target plant cucumber (Cucumis sativus L.) and one monocot nontarget plant wheat (Triticum aestivum L.) was also evaluated. 


\section{Materials and Methods}

\subsection{Materials}

Selenium (IV) dioxide $\left(\mathrm{SeO}_{2}\right)$, 7-diethylamino-4-methylcoumarin, sodium borohydride $\left(\mathrm{NaBH}_{4}\right)$, succinic anhydride, potassium carbonate $\left(\mathrm{K}_{2} \mathrm{CO}_{3}\right)$, 4-dimethylaminopyridine (DMAP), 1-ethyl-3-(3-dimethylaminopropyl) carbodiimide(EDC), N-hydroxysuccinimide (NHS) and 2,4-D were obtained from Aladdin Reagent Co. (Shanghai, China). Carboxymethyl chitosan with a degree of substitution of 0.8 was purchased from Shanghai Yuanye Biological Co. (Shanghai, China). The degree of deacetylation (DD) was determined to be 0.96 , according to a method described in the literature [41]. Dioxane, tetrahydrofuran (THF), ethanol $(\mathrm{EtOH}), \mathrm{HCl}$, dichloromethane $\left(\mathrm{CH}_{2} \mathrm{Cl}_{2}\right)$, chloroform $\left(\mathrm{CHCl}_{3}\right)$, dimethylsulfoxide (DMSO), petroleum ether and ethyl acetate were purchased from Beijing Chemical Reagent Co (Beijing, China). Dialysis bag (MWCO, $3.5 \mathrm{kDa}$ ) was obtained from Union Carbide Co. (Danbury, CT, USA). Nitrogen was provided by Guiyang Shenjian Gas Company (Guiyang, China). Deionized water was used throughout the work.

\subsection{Synthesis of 7-Diethylamino-4-Hydroxymethylcoumarin (1)}

The 7-diethylamino-4-hydroxymethylcoumarin (1) was synthesized in a similar procedure according to the literature [30,42]. $\mathrm{SeO}_{2}(4.44 \mathrm{~g}, 40 \mathrm{mmol})$ was added to a solution of 7-diethylamino-4-methylcoumarin $(4.62 \mathrm{~g}, 20 \mathrm{mmol})$ in dioxane $(100 \mathrm{~mL})$. The reaction mixture was refluxed at $90{ }^{\circ} \mathrm{C}$ under vigorous stirring with a protective atmosphere of nitrogen for $24 \mathrm{~h}$, and then the reaction mixture was filtered and the filtrate was concentrated under reduced pressure. The obtained dark-brown residue was dissolved in $100 \mathrm{~mL}$ of THF/EtOH mixture (1:1), and NaBH4 (1.52 g, $40 \mathrm{mmol}$ ) was added slowly. The solution was stirred at room temperature for $4 \mathrm{~h}$ and then the suspension was carefully neutralized with $1 \mathrm{M} \mathrm{HCl}$. Solvents were almost totally removed under vacuum. The residue was diluted with $\mathrm{CH} 2 \mathrm{Cl} 2$ and extracted three times with $0.5 \mathrm{M} \mathrm{K} 2 \mathrm{CO} 3$. The organic extracts were concentrated and purified by column chromatography (petroleum ether/ethyl acetate $=2: 1)$ to obtain compound (1) as a reddish brown solid with a yield of $56 \%$ M.P. $\left({ }^{\circ} \mathrm{C}\right): 131.6$. ${ }^{1} \mathrm{H}$ NMR (400 MHz, DMSO-d $\left.d_{6}, \mathrm{ppm}\right): \delta 7.43(\mathrm{~d}, 1 \mathrm{H}), 6.66(\mathrm{dd}, 1 \mathrm{H}), 6.52(\mathrm{~d}, 1 \mathrm{H}), 6.07(\mathrm{~s}, 1 \mathrm{H}), 5.53(\mathrm{t}, 1 \mathrm{H})$, 4.67(d, 2H), $3.42(\mathrm{q}, 4 \mathrm{H}), 1.11(\mathrm{t}, 6 \mathrm{H}) .{ }^{13} \mathrm{C}$ NMR (100 MHz, DMSO- $\left.d_{6}, \mathrm{ppm}\right): \delta 161.20,156.93,155.65$, 150.18, 125.09, 108.53, 105.68, 103.87, 96.76, 59.07, 43.99, 12.35.UV-vis: $\lambda_{\max }=375 \mathrm{~nm}$; Anal.: calcd for $\mathrm{C}_{14} \mathrm{H}_{17} \mathrm{NO}_{3}$ (247): $\mathrm{C}, 68.02 ; \mathrm{H}, 6.88 ; \mathrm{N}, 5.67 \%$. Found: $\mathrm{C}, 64.67 ; \mathrm{H}, 5.53 ; \mathrm{N}, 5.18 \%$.

\subsection{Synthesis of (7-Diethylaminocoumarin-4-Yl)Methyl Succinate (DEACMS)}

First, 7-diethylamino-4-hydroxymethylcoumarin (1) (2.47 g, $10 \mathrm{mmol})$, succinic anhydride ( $2 \mathrm{~g}$, $20 \mathrm{mmol})$ and DMAP $(0.61 \mathrm{~g}, 5 \mathrm{mmol})$ were dissolved in $\mathrm{CHCl}_{3}(100 \mathrm{~mL})$. The reaction mixture was refluxed at $55^{\circ} \mathrm{C}$ under vigorous stirring for $24 \mathrm{~h}$. After evaporation of $\mathrm{CHCl}_{3}$ under reduced pressure, the residual mixture was washed three times with $1 \mathrm{M} \mathrm{HCl}$ and then extracted with saturated $\mathrm{NaHCO}_{3}$ solution. The basic aqueous phase was washed with ether and acidified to $\mathrm{pH} 5.0$ with $1 \mathrm{M} \mathrm{HCl}$. The precipitate was collected and dried in vacuum at $40^{\circ} \mathrm{C}$ for $24 \mathrm{~h}$ to give (7-diethylaminocoumarin-4-yl)methyl succinate (DEACMS) as a yellow solid with a yield of $47 \%$ M.P.

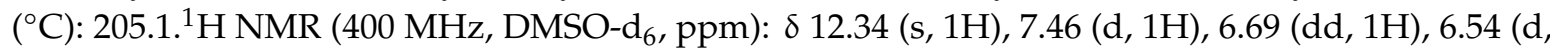
1H), $6.01(\mathrm{~s}, 1 \mathrm{H}), 5.30(\mathrm{~s}, 2 \mathrm{H}), 3.43(\mathrm{q}, 4 \mathrm{H}), 2.68(\mathrm{t}, 2 \mathrm{H}), 2.54(\mathrm{t}, 2 \mathrm{H}), 1.12(\mathrm{t}, 6 \mathrm{H}) .{ }^{13} \mathrm{C} \mathrm{NMR}(100 \mathrm{MHz}$, DMSO-d ${ }_{6}$, ppm): $\delta 173.55,171.89,160.67,155.79,150.59,150.45,125.49,108.75,105.24,104.98,96.83$, 61.32, 44.04, 28.66, 12.35.UV-vis: $\lambda_{\max }=381 \mathrm{~nm}$; Anal.: calcd. for $\mathrm{C}_{18} \mathrm{H}_{21} \mathrm{NO}_{6}(347): \mathrm{C}, 62.25 ; \mathrm{H}, 6.05 ; \mathrm{N}$, 4.03\%. Found: C, 60.09; H, 5.34; N, 3.92\%.

\subsection{Synthesis of Carboxymethyl Chitosan-(7-Diethylaminocoumarin-4-Yl)Methyl Succinate (CMCS-DEACMS)}

The carboxymethyl chitosan-(7-diethylaminocoumarin-4-yl)methyl succinate (CMCS-DEACMS) (CMCS-DEACMS) was synthesized in a similar procedure according to the literature [43]. Typically, 
$20 \mathrm{~mL}$ of hydroalcoholic (water/EtOH 1:1, v/v) solution of CMCS (100 mg) was prepared. Meanwhile, DEACMS, EDC and NHS (molar ratio of DEACMS:EDC:NHS 1:1:1) were added into DMSO (5.0 mL) in sequence, and the reaction mixture was stirred at room temperature for $1 \mathrm{~h}$ to activate the carboxyl groups of DEACMS. Then, the mixture was dropwise added into the CMCS solution and stirred at room temperature for $24 \mathrm{~h}$. The resultant mixture was extensively dialyzed in deionized water for $48 \mathrm{~h}$. Finally, CMCS-DEACMS were obtained by lyophilization. All the above procedures were performed in the dark. Three samples with varying molar ratios of DEACMS to glucosamine units of CMCS 1:3, 1:5 and 1:7 were prepared and labeled as CMCS-DEACMS-1, CMCS-DEACMS-2 and CMCS-DEACMS-3.

\subsection{Preparation of CMCS-DEACMS Micelles}

The dry CMCS-DEACMS (10.0 mg) was dissolved in $10 \mathrm{~mL}$ deionized water, and the solution was stirred at room temperature for $6 \mathrm{~h}$, followed by sonication using a probe-type ultrasonicator (Scientz-IID, Ningbo Xinzhi Bio-tech Co., Ningbo, China) at $350 \mathrm{~W}$ using a pulse function (pulse on $2.0 \mathrm{~s}$, pulse off $2.0 \mathrm{~s}$ ) in ice-bath for $10 \mathrm{~min}$. The obtained micelle solution was filtered through a $0.45 \mu \mathrm{m}$ Millipore filter to remove larger particles. All operations were carried out in the dark.

\subsection{Characterization of the CMCS-DEACMS Micelles}

The critical micelle concentration (CMC) value of the amphiphilic CMCS-DEACMS was determined by fluorescence measurement using pyrene as a probe [44]. Pyrene was firstly dissolved in acetone, and $0.5 \mathrm{~mL}$ of $6 \times 10^{-6} \mathrm{M}$ pyrene solution was added to volumetric flasks. After the acetone was evaporated under $50{ }^{\circ} \mathrm{C}, 5 \mathrm{~mL}$ of fresh CMCS-DEACMS solutions at concentrations ranging from 0.2 to $2000 \mu \mathrm{g} / \mathrm{mL}$ were added into the aforementioned volumetric flasks of pyrene. The solution was ultrasonicated for $30 \mathrm{~min}$ and shaken overnight to reach the solubilization equilibrium of pyrene before test. Then, the fluorescence spectra of solutions were recorded on a Cary Eclipse fluorescence spectrophotometer (Agilent, Santa Clara, CA, USA) at room temperature. The excitation wavelength was $333 \mathrm{~nm}$, and the fluorescence emission spectra were recorded from 350 to $600 \mathrm{~nm}$. From the pyrene emission spectra, the intensity ratio of first peak $\left(I_{1}, 373 \mathrm{~nm}\right)$ to third peak $\left(I_{3}, 383 \mathrm{~nm}\right)$ was used to estimate the polarity of the pyrene microenvironment [45]. By the profile of $I_{1} / I_{3}$ as a function of concentration (in logarithmic scale), the CMC value was determined from the junction of the horizontal tangent through points at low concentrations with the tangent to the curve at the inflection point.

The hydrodynamic diameter of the CMCS-DEACMS micelles was determined by dynamic light scattering (DLS) experiments with a laser light scattering spectrometer (BI-200SM, Brookhaven, MS, USA). The measurements were performed with the scattering angle of $90^{\circ}$ at $25^{\circ} \mathrm{C}$. All the solutions were filtered through a $0.45 \mu \mathrm{m}$ Millipore filter before DLS experiments. Morphological evaluation was performed on a JEM-2100 transmission electron microscope (JEOL, Tokyo, Japan). The NMR measurements were carried out on a JNM-ECZ400 spectroscope (JEOL, Tokyo, Japan). The FTIR spectroscopy was performed on a Thermo Scientific Nicolet iS50 spectrometer (Thermo Fisher, Madison, WI, USA), and the spectra were recorded using 32 scans over a $4000-650 \mathrm{~cm}^{-1}$ range. The decomposition pattern of samples was analyzed by using a TG209F1 Libra Thermal Gravimetric Analyser (Netzsch, Selb, Germany). The samples were heated from room temperature to $800{ }^{\circ} \mathrm{C}$ at a rate of $10^{\circ} \mathrm{C} / \mathrm{min}$ using nitrogen gas $\left(\mathrm{N}_{2}\right)$. The UV-vis absorption and emission spectra of CMCS-DEACMS solution were recorded on a UV-2700 UV/vis spectrophotometer (Shimadzu, Kyoto, Japan) and an Agilent Cary Eclipse spectrofluorometer (Agilent, Santa Clara, CA, USA), respectively. The Stokes' shift was calculated from the difference in the absorption and emission maxima of the micelles [28].

\subsection{Photoresponse and Stability of the CMCS-DEACMS Micelles}

A metal halide lamp (MH400, Bashida Lighting Electric Co., Lanxi, China) was used as simulator to mimic natural sunlight, and the distance between the lamp and micelles was set as $40 \mathrm{~cm}$. The photo response of the CMCS-DEACMS micelles was monitored by UV-vis, fluorescence, DLS and TEM 
measurements after irradiation under simulated sunlight. The micelle solutions kept in the dark were used as a control.

\subsection{Preparation of 2,4-D Loaded Micelles}

The 2,4-D loaded CMCS-DEACMS-2 micelles were prepared according to the literature [22,46]. CMCS-DEACMS $(10.0 \mathrm{mg}$ ) was dissolved in buffer solution ( $\mathrm{pH} 7.4)$ to obtain a concentration of $1 \mathrm{mg} / \mathrm{mL}$. Then, $1 \mathrm{~mL}$ of 2,4-D/methanol solution $(12 \mathrm{mg} / \mathrm{mL})$ was added dropwise into the CMCS-DEACMS-2 micelle solution under vigorous stirring for $1 \mathrm{~h}$, followed by ultrasonic treatment for $10 \mathrm{~min}$. Then, the whole solution was transferred into a dialysis bag $(\mathrm{MWCO}, 3.5 \mathrm{kDa})$ and dialyzed against the same buffer for $12 \mathrm{~h}$. Finally, dialyzed products were filtrated through a $0.45 \mu \mathrm{m}$ Millipore filter and lyophilized to obtain 2,4-D loaded micelles.

The amount of 2,4-D encapsulated in the micelles was determined by HPLC (LC-2030, Shimadzu, Japan) using a C18 bonded reverse phase column with a mobile phase of methanol-water mix (60:40, $\mathrm{pH} 3.0)$ at a flow rate of $1.0 \mathrm{~mL} / \mathrm{min}$. The peak was detected at $285 \mathrm{~nm}$ with a UV detector. The encapsulation efficiency (EE) and loading content (LC) of 2,4-D in the CMCS-DEACMS micelles were calculated as follows [47]:

$$
\begin{aligned}
& \text { EE }(\%)=\frac{\text { weight of loaded } 2,4-\mathrm{D}}{\text { weight in feed }} \times 100 \% \\
& \text { LC }(\%)=\frac{\text { weight of loaded } 2,4-\mathrm{D}}{\text { weight of micelles }} \times 100 \%
\end{aligned}
$$

\subsection{Controlled Release of 2,4-D Loaded Micelles}

Lyophilized 2,4-D loaded micelle samples $(5.0 \mathrm{mg}$ ) were dissolved in $5.0 \mathrm{~mL}$ of buffer solution ( $\mathrm{pH} 7.4$ ) and then placed into a dialysis bag. The dialysis bag was immersed in $100 \mathrm{~mL}$ of the same buffer. The system was exposed to simulated sunlight under mild shaking at $25^{\circ} \mathrm{C}$. At predetermined time intervals, $1 \mathrm{~mL}$ dialysis solution was withdrawn and analyzed by HPLC; then, $1 \mathrm{~mL}$ fresh buffer was added back. The samples without irradiation upon simulated sunlight were also used as a control. The cumulative amount of released 2,4-D was calculated against time according to the following equation:

$$
\text { Cumulative release }(\%)=\frac{V_{\mathrm{e}} \sum_{i=0}^{n-1} C_{\mathrm{i}}+V_{0} C_{\mathrm{n}}}{m_{\text {pesticide }}} \times 100 \%
$$

where $V_{\mathrm{e}}$ and $V_{0}$ are the sampled volume taken at a predetermined time interval $\left(V_{\mathrm{e}}=1 \mathrm{~mL}\right)$ and the volume of release solution $\left(V_{0}=100 \mathrm{~mL}\right)$, respectively; $C_{\mathrm{n}}(\mathrm{mg} / \mathrm{mL})$ is the 2,4-D concentration in the release medium at time $n$. The $m_{\text {pesticide }}(\mathrm{mg})$ is the total amount of pesticide encapsulated in the micelles.

\subsection{Bioactivity of 2,4-D Loaded Micelles}

The bioactivity of 2,4-D loaded micelles was evaluated by taking advantage of one target dicot plant cucumber (Cucumis sativus L.) and one nontarget monocot plant wheat (Triticum aestivum L.), according to the laboratory bioassay of 2,4-D nanocarriers reported by Cao et al. [48]. For cucumber bioassay study, similarly sized germinated seeds were placed in a Petri dish with a filter paper moistened with $10 \mathrm{~mL}$ of 2,4-D loaded micelle solutions at a concentration of the active ingredient equivalent to the field application rate $(0.6 \mathrm{~kg} / \mathrm{ha})$. Control plants were also grown in Petri dishes and treated with the same amount of free 2,4-D and deionized water. The Petri dishes were incubated in a room with humidity of around $80 \%$. Day and night temperatures were around 28 and $20{ }^{\circ} \mathrm{C}$, respectively. All the Petri dishes were exposed to natural sunlight, simulating the open field planting. Additionally, the Petri dishes were exposed to simulated sunlight for $2 \mathrm{~h}$ everyday throughout the 
experimental period. Same amount of distilled water was applied to each Petri dish for daily watering. After 10 days, the root length and fresh weight were recorded to assess the bioactivity of the target plant.

The bioactivity for the nontarget plant wheat was tested in pot experiments. Ten seeds of wheat were sown in each pot $(17.0 \mathrm{~cm}$ high with diameter of $15.0 \mathrm{~cm})$ and grown in the same room as cucumber. Same amount of distilled water was applied to each pot for daily watering. One week after sowing, the 2,4-D loaded micelle solution was applied postemergence at an application rate of $2.5 \mathrm{~kg} / \mathrm{ha}$ (the maximum concentration recommended for field application of 2,4-D) [49]. The samples treated with same amount of free 2,4-D and deionized water were used as controls. After another week, the plant height and fresh weight of the aerial part of the wheat were measured to monitor the response of nontarget plants to the herbicide nanocarriers.

\section{Results and Discussion}

\subsection{Synthesis and Characterization of CMCS-DEACMS}

The light-responsive carboxymethyl chitosan-(7-diethylaminocoumarin-4-yl) methyl succinate (CMCS-DEACMS) conjugate was synthesized from a three-step route starting from commercially available chemicals, as shown in Scheme 1A. Oxidation of 7-diethylamino-4-methylcoumarin with $\mathrm{SeO}_{2}$ and the following reduction by $\mathrm{NaBH}_{4}$ afforded the intermediate 1. Then, 7-Diethylamino -4-hydroxymethylcoumarin (DEACMS) was prepared by the esterification reaction of $\mathbf{1}$ with succinic anhydride, with DMAP as the catalyst, according to the literature [50,51]. The chemical structures of the products at each step were characterized with NMR (Figures S1-S6 from Supplementary Materials). Then, the CMCS-DEACMS was synthesized by the reaction of the carboxyl group of DEACMS with the amine group of CMCS via an amide linkage using EDC/NHS as coupling agents.

(A)
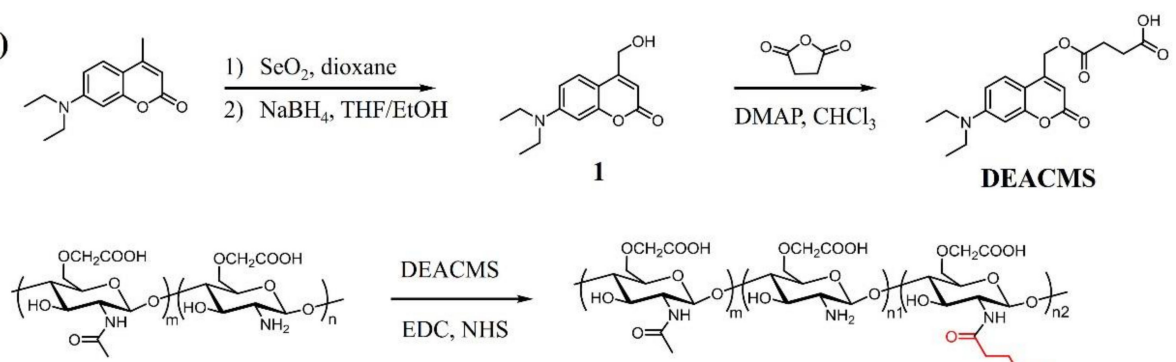

DEACMS

(B)
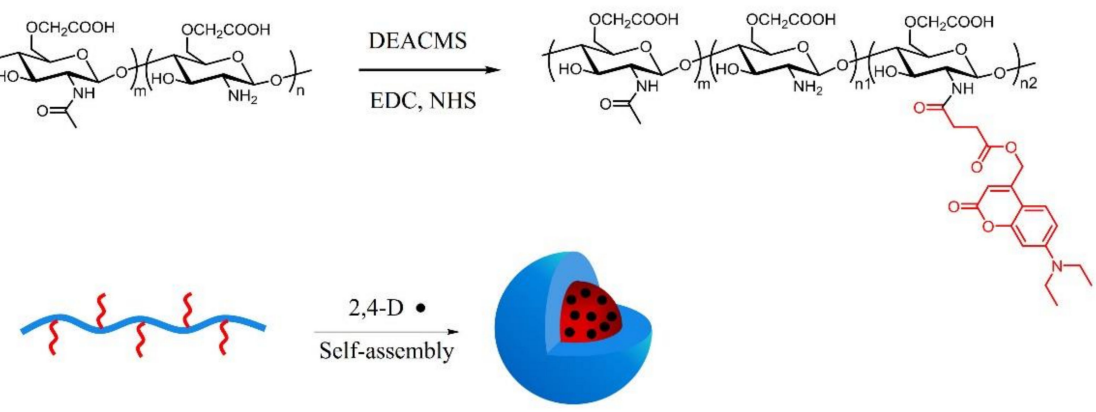

Scheme 1. Schematic illustration of (A) the synthesis route of CMCS-DEACMS and (B) the assembly process of CMCS-DEACMS.

Formation of CMCS-DEACMS was characterized by ${ }^{1} \mathrm{H}$ NMR and FTIR (Figure 1A). In the FTIR spectrum of CMCS, the $3300 \mathrm{~cm}^{-1}$ broad absorption band was attributed to the overlapped stretching vibrations of $\mathrm{O}-\mathrm{H}$ and $\mathrm{N}-\mathrm{H}$. The absorption bands at $2890 \mathrm{~cm}^{-1}$ and $1322 \mathrm{~cm}^{-1}$ could be assigned to the respective $\mathrm{C}-\mathrm{H}$ stretching and bending vibration [43]. The absorption peak at $1051 \mathrm{~cm}^{-1}$ represents the stretching vibration of $\mathrm{C}-\mathrm{O}$, indicating that the carboxymethyl group mainly occurred in the $\mathrm{C}-6$ position [52]. Two absorption bands at $1589 \mathrm{~cm}^{-1}$ and $1416 \mathrm{~cm}^{-1}$ could be assigned to the asymmetric and symmetric stretching vibrations of $-\mathrm{COO}^{-}$, respectively [53]. Compared with CMCS, a new shoulder peak assigned to the carbonyl of ester group was observed at $1698 \mathrm{~cm}^{-1}$ in the spectrum of CMCS-DEACMS. The appearance of an absorption band at $2929 \mathrm{~cm}^{-1}$ corresponded to $\mathrm{C}-\mathrm{H}$ stretching of DEACMS. 
The chemical structures of CMCS and CMCS-DEACMS were further confirmed by ${ }^{1} \mathrm{H}$ NMR, as shown in Figure 1B. The proton signals of CMCS in $\mathrm{D}_{2} \mathrm{O}$ were in accordance with previous reports [22]. The resonances at 3.1-3.8 ppm were assigned to the ring protons of the CMCS backbone $(\mathrm{H} 3, \mathrm{H} 4, \mathrm{H} 5, \mathrm{H} 6)$, and the peaks at 2.3-2.5 ppm were ascribed to the proton of $\mathrm{H} 2$ [43,54]. Chemical shift values at $1.88 \mathrm{ppm}$ and at $4.3 \mathrm{ppm}$ corresponded to the protons of the acetamido group and $-\mathrm{CH}_{2} \mathrm{COO}^{-}$substituted on the $\mathrm{C} 6$ hydroxyl group $[54,55]$. Compared to $\mathrm{CMCS}$, the appearance of new signals in the region of 6.0-7.5 ppm for CMCS-DEACMS corresponding to the phenyl ring of DEACMS confirmed the successful chemical linkage of DEACMS to CMCS. All these results confirm the successful conjugation between DEACMS and CMCS.

The degree of substitution (DS) can be defined as the number of DEACMS per 100 glucosamine units of CMCS. The DS of DEACMS was determined by the peak areas of the phenyl ring of DEACMS at $\delta 6.00$ to $8.00 \mathrm{ppm}$, acetamido group of CMCS $(\delta 1.88 \mathrm{ppm})$ and the deacetylation degree of CMCS $[53,56]$. The DS of DEACMS on CMCS were $10.6 \%, 7.3 \%$ and $3.5 \%$ for DEACMS-CMCS- 1 , DEACMS-CMCS-2 and DEACMS-CMCS-3, respectively. Apparently, it increases with the increase in the feed ratio of DEACMS and CMCS.

Figure 2 displays the TGA thermograms of CMCS and CMCS-DEACMS. It can be seen that both CMCS and CMCS-DEACMS mainly underwent two decomposition stages. The main loss in the first stage up to $150^{\circ} \mathrm{C}$ was due to the loss of adsorbed water. The second decomposition of CMCS, starting from 200 to $800^{\circ} \mathrm{C}$, was due to the decomposition of the polysaccharide [39]. The DTG curves show that the maximum decomposition rate of CMCS occurred at the peak of $267^{\circ} \mathrm{C}$, whereas the CMCS-DEACMS displayed a maximum weight loss rate at $296^{\circ} \mathrm{C}$, which indicates that the thermal stability was enhanced after introduction of the pendant DEACMS groups.
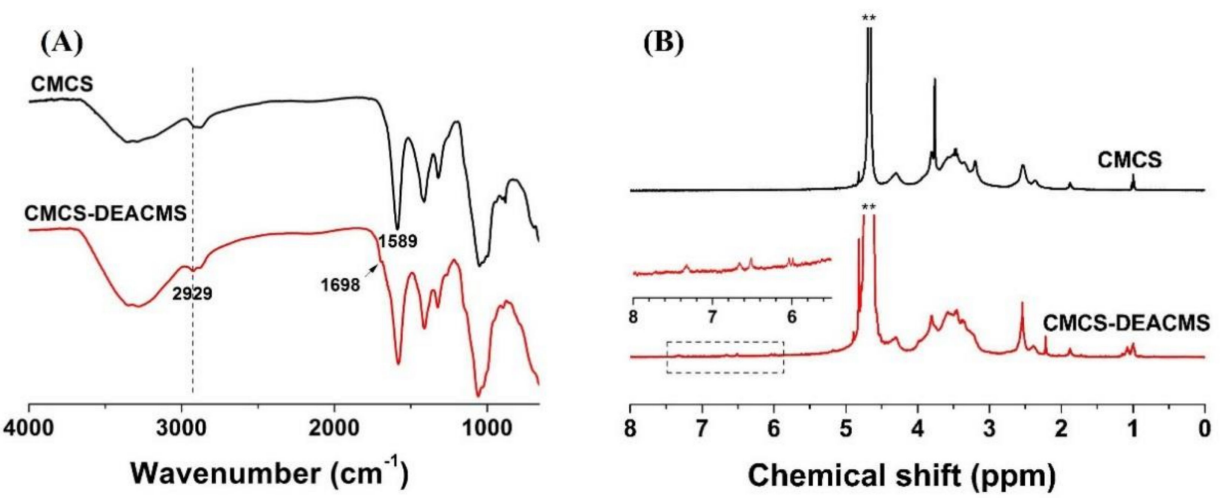

Figure 1. Characterization of CMCS-DEACMS conjugate. (A) FTIR spectra of CMCS and CMCS-DEACMS; (B) ${ }^{1} \mathrm{H}$ NMR spectra of CMCS and CMCS-DEACMS in $\mathrm{D}_{2} \mathrm{O}$, inset is an enlargement of the CMCS-DEACMS spectrum from $\delta 6.00$ to 8.00 to show DEACMS peaks. Asterisks $\left(^{* *}\right)$ indicate the solvent peak.
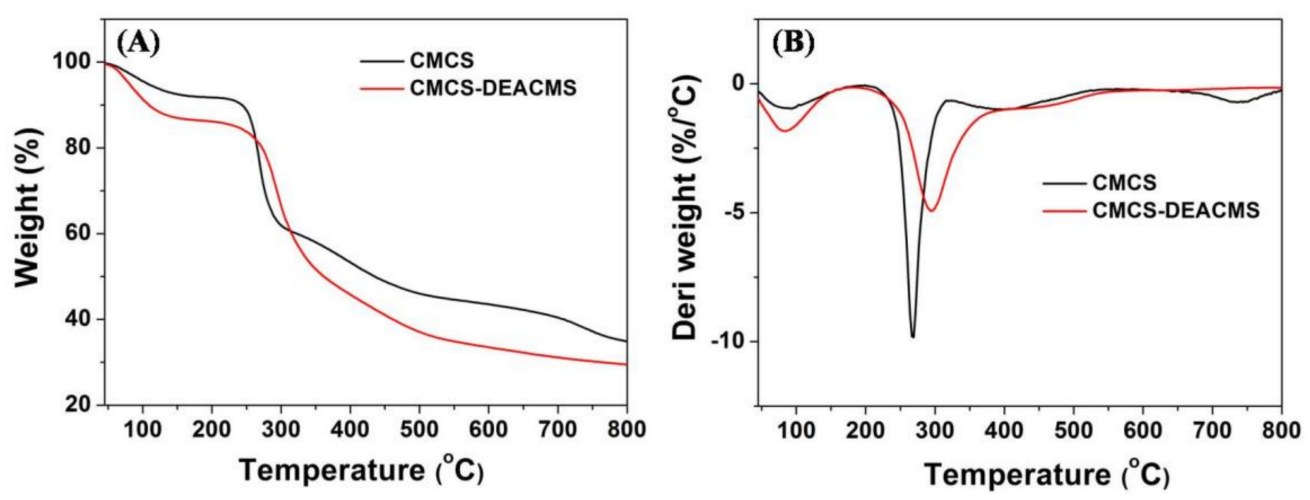

Figure 2. (A) TGA and (B) DTG curves of CMCS and CMCS-DEACMS. 


\subsection{Self-Assembly Behavior of CMCS-DEACMS Micelles}

The synthesized CMCS-DEACMS conjugate is a typical amphiphilic polymer containing both hydrophobic coumarin moieties and a hydrophilic CMCS backbone. When the concentration is above CMC, it will self-assemble into a core-shell micelle structure in aqueous media, as illustrated in Scheme 1B. The CMC of the CMCS-DEACMS conjugate was investigated by using pyrene as a fluorescence probe. Pyrene molecules preferably locate in the hydrophobic region of CMCS-DEACMS micelles rather than the aqueous phase due to their strong hydrophobic nature and very low solubility in water [33]. The variation in the intensity ratio of $I_{1}(373 \mathrm{~nm})$ to $I_{3}(383 \mathrm{~nm})$ is quite sensitive to the microenvironment where pyrene is located [45]. Figure $3 \mathrm{~A}$ shows the profile of $I_{1} / I_{3}$ against polymer concentration for CMCS-DEACMS-2, and the abrupt decrease in $I_{1} / I_{3}$ corresponds to CMC. The CMC values were determined by the crossover point to be $0.013,0.027$ and $0.042 \mathrm{mg} / \mathrm{mL}$ for CMCS-DEACMS- 1 (Figure S7), CMCS-DEACMS-2 and CMCS-DEACMS-3 (Figure S8), respectively. The CMC values are comparable with other CMCS-based amphiphilic copolymers [22,44]. The decrease in CMC with the increase in the DS of DEACMS can be attributed to the higher content of the hydrophobic coumarin component in the CMCS-DEACMS, which resulted in fewer molecules being available to form stable micelles. This phenomenon is consistent with previous results reported by Yan et al. [23].
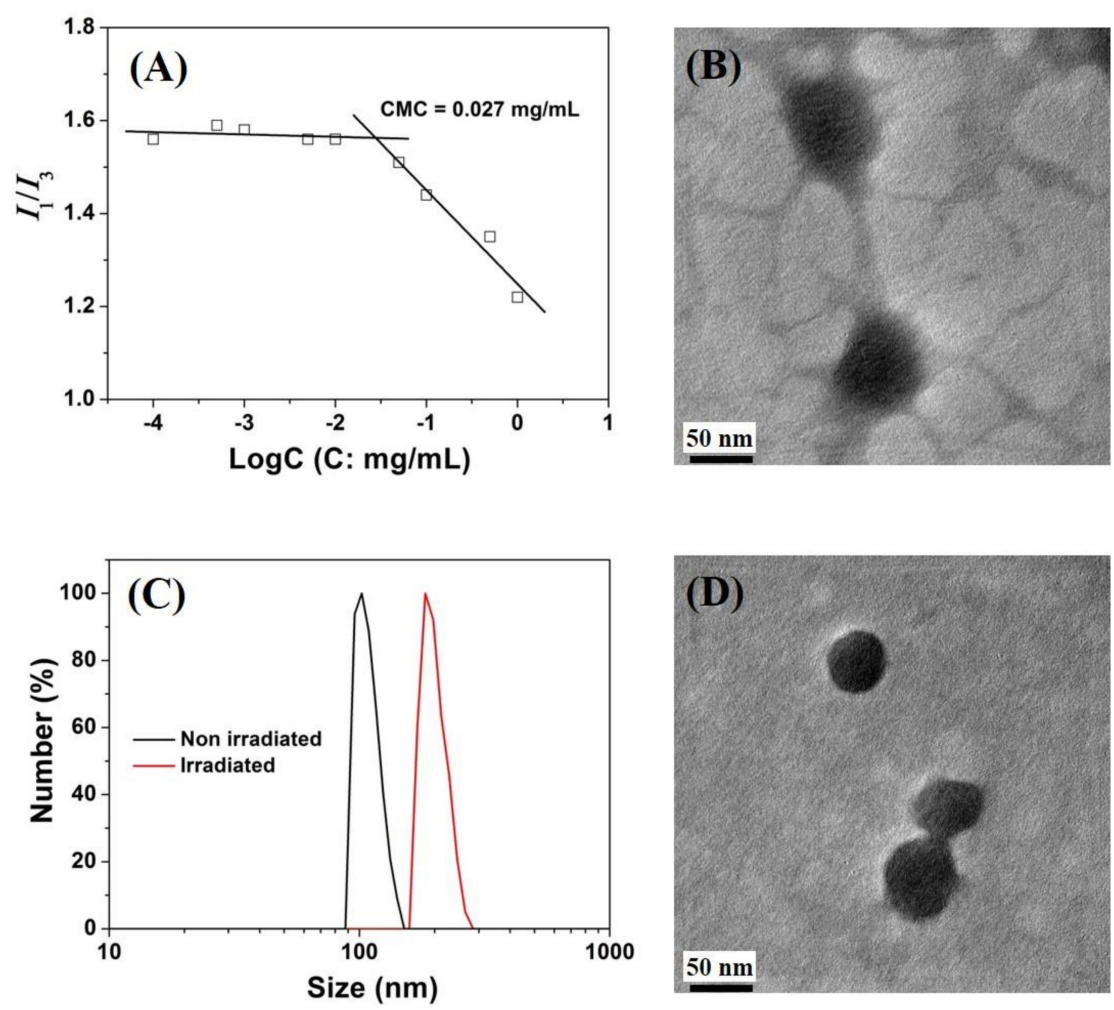

Figure 3. (A) Intensity ratio $\left(I_{1} / I_{3}\right)$ of the pyrene emission spectra versus the logarithm concentration of CMCS-DEACMS-2 micelles; (B) TEM images of CMCS-DEACMS-2 micelles; (C) DLS results of CMCS-DEACMS-2 micelles before and after irradiation under simulated sunlight; (D) TEM images of CMCS-DEACMS-2 micelles after irradiation under simulated sunlight.

The morphology and hydrodynamic diameter of the self-assembled CMCS-DEACMS-2 micelles were characterized by TEM (Figure 3B) and DLS (Figure 3C), respectively. According to TEM images, the CMCS-DEACMS-2 formed spherical micelles with diameters of around $70 \mathrm{~nm}$. DLS results showed a monomodal size distribution with average hydrodynamic diameters of $109 \mathrm{~nm}$, a larger value than the size obtained from the TEM experiment, which was due to shrinkage of the micelles during the drying process of the TEM samples. The samples were further monitored for up to 10 days, showing a slightly higher value of around $113 \mathrm{~nm}$, suggesting temporal stability. 


\subsection{Light-Responsive Property of the Micelles}

The CMCS-DEACMS micelles in aqueous solution were exposed to simulated sunlight at regular intervals, and the photochemical reaction was followed by UV-vis and fluorescence spectroscopy (Figure 4). The absorption and emission spectra of DEACMS are shown in Figure S9 as a contrast. In the UV-vis spectra of CMCS-DEACMS, one prominent absorption band with a maximum at $391 \mathrm{~nm}$ can be observed, a spectral feature corresponding to the absorption of the coumarin units. These results are in accordance with other polymers with photocleavable coumarin units $[14,30]$. As expected, the CMCS-DEACMS sample is photochemically active in the visible region due to the electron-donating diethylamino groups $[29,57]$. Under irradiation with simulated sunlight, the intensity of peak absorption decreased and maximum absorption wavelength hypsochromically shifted to $378 \mathrm{~nm}$, indicating that the photolysis reaction took place. Further, the emission spectra showed that the CMCS-DEACMS micelles are fluorescent in nature, with a maximum emission wavelength at $500 \mathrm{~nm}$ and a Stokes' shift of $109 \mathrm{~nm}$. Similar emission intensity decreases and hypsochromic shifts from $500 \mathrm{~nm}$ to $488 \mathrm{~nm}$ were also detected in the fluorescence spectra. The increasing trend in the intensity of emission maxima upon light irradiation is in accordance with previously reported polyphosphazenes with pendant coumarin groups [30]. The hypsochromic shift of the absorption and emission maxima indicates the decomposition of the coumarin-containing CMCS-DEACMS to the corresponding photoproducts 1 , whose maximum absorption and emission wavelength were $375 \mathrm{~nm}$ and $457 \mathrm{~nm}$ (Figure S10), respectively. On the contrary, aqueous solution of CMCS-DEACMS micelles showed negligible change during $24 \mathrm{~h}$ in the dark both in the UV-vis and emission spectra, indicating its stability in the dark (Figures S11 and S12). Further, we also monitored the photolysis of CMCS-DEACMS micelles using ${ }^{1} \mathrm{HNMR}$ spectroscopy. The signals at 6.0-7.5 ppm ascribed to the coumarin groups can hardly be observed after irradiation under simulated sunlight, indicating the occurrence of the photocleavage reaction (Figure S13).
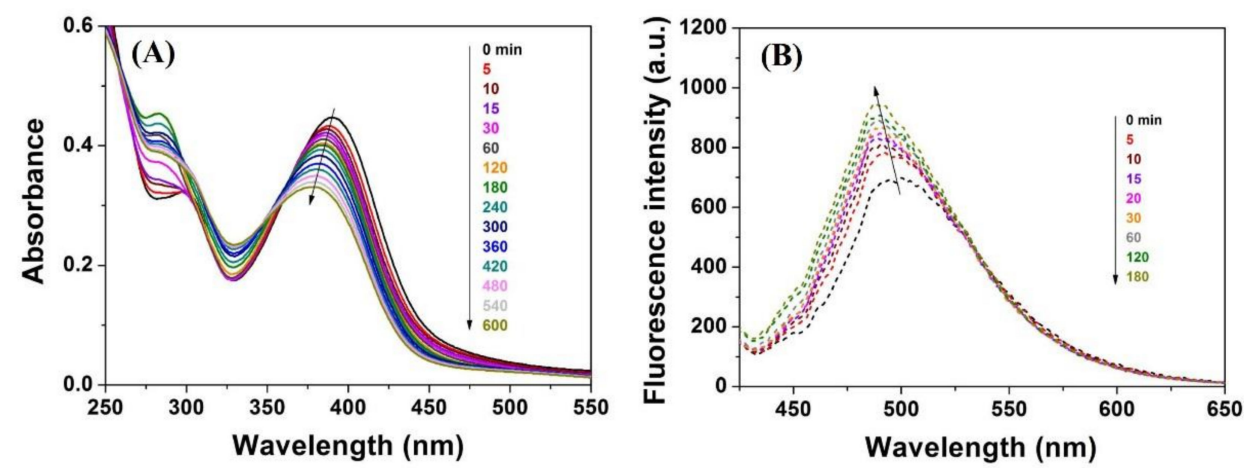

Figure 4. (A) UV-vis and (B) emission spectra of CMCS-DEACMS-2 micelles upon irradiation under simulated sunlight with different irradiation times.

The mechanism of the photolysis of the CMCS-DEACMS involves initial heterolysis of the C-O ester bond (photo $S_{N} 1$ ) to produce an ion pair of coumarinyl methyl carbocation and a carboxylate anion on $\mathrm{N}$-substituted CMCS. Finally, after separation of the ion pair in water, the methylenic carbocation is trapped by water to yield compound $\mathbf{1}$, while the carboxylate anion abstracts a proton from water to yield the corresponding CMCS derivative [14,28], as illustrated in Scheme 2.

The light-responsive properties of the micelles were further tracked by TEM and DLS (Figure 4). After exposure under simulated sunlight for $5 \mathrm{~h}$, the average hydrodynamic diameter of micelles increased from $109 \mathrm{~nm}$ to $200 \mathrm{~nm}$, arising from the photocleavage of the coumarin moieties at the micelles' core. This photolysis reaction left hydrophilic terminal carboxyl groups and resulted in swelling of the micelles, as observed for other coumarin-based micelles or nanoparticles [58,59]. TEM images confirm the light-induced morphological change; micelles appeared to be smaller and the core-shell structures were still maintained even after irradiation under simulated sunlight. 


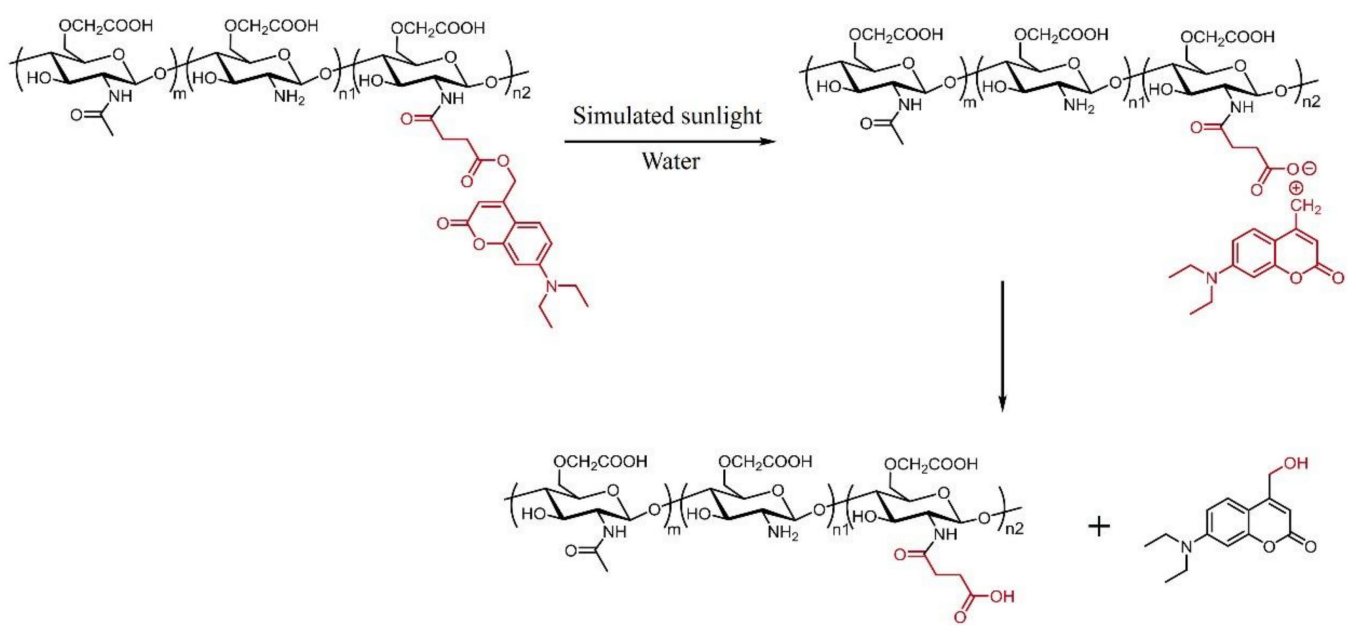

Scheme 2. Mechanism of the photolysis of the CMCS-DEACMS upon simulated sunlight.

\subsection{Light-Controlled Release of 2,4-D}

Pesticide carriers with controllable release in response to environmental stimuli are highly attractive in terms of smart "on-demand" delivery and increased efficacy. In previous work, the utilization of amphiphilic micelles for pesticide loading and controlled release has been reported $[22,33,60]$. In the present work, CMCS-DEACMS-2 was utilized to investigate the pesticide loading and light-responsive release profile by using herbicide 2,4-D as a model pesticide. The EE and LC of the 2,4-D loaded CMCS-DEACMS micelles were found to be $7.25 \%$ and $8.7 \%$, respectively. The EE and LC can be readily regulated through adjusting the concentration of the 2,4-D/methanol feed solution. Other LC values were also determined to be $6.72 \%$ and $9.54 \%$ for $2,4-\mathrm{D} /$ methanol feed solutions with concentrations of $8 \mathrm{mg} / \mathrm{mL}$ and $16 \mathrm{mg} / \mathrm{mL}$, respectively. This indicates that a high concentration of the initial pesticide solution would result in a high LC [33]. The light-responsive release curves are presented in Figure 5. The simulated sunlight used in this work was applied as a commercial plant growth light with a spectral output of 320-800 nm, among which the CMCS-DEACMS micelles were photochemically active. Without irradiation upon simulated sunlight, around $65 \%$ of the loaded 2,4-D is released within $500 \mathrm{~min}$. However, with irradiation upon simulated sunlight, approximately $90 \%$ of the loaded 2,4-D is released within the same period. It is indicated that the release was promoted by irradiation upon simulated sunlight, which derived from the rapid escape of 2,4-D from the destabilized CMCS-DEACMS micelles due to the photocleavage of coumarin groups.

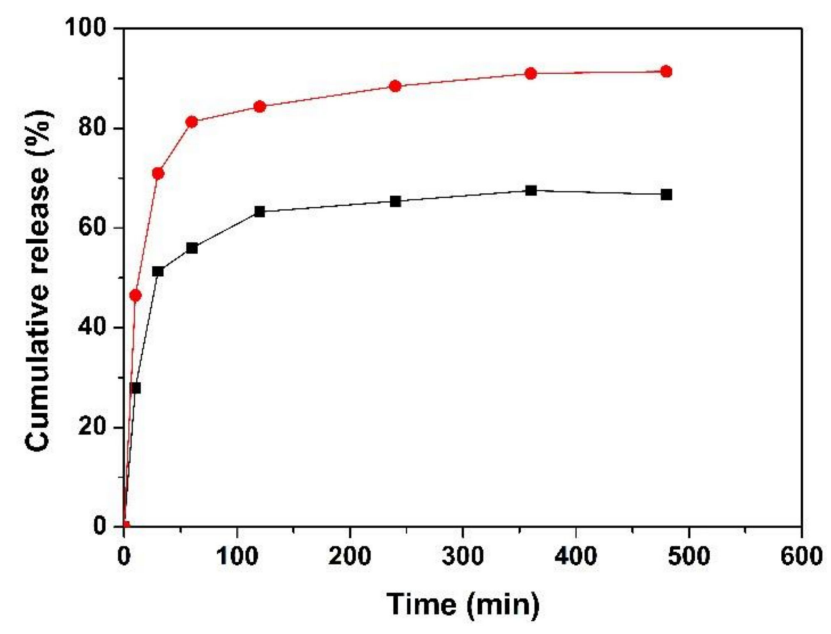

Figure 5. Release of 2,4-D from the CMCS-DEACMS-2 micelles under simulated sunlight irradiation

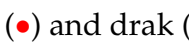




\subsection{Bioactivity Activity}

The bioactivity of the 2,4-D-containing CMCS-DEACMS micelles was compared to free 2,4-D and deionized water in laboratory using one dicot target plant cucumber (Cucumis sativus L.) and one monocot nontarget plant wheat (Triticum aestivum L.), according to a previous report [48]. The 2,4-D-containing micelles showed effective root growth inhibition of cucumber plant, as well as free 2,4-D (Figure 6). After 10 days of experimentation, the 2,4-D-containinh CMCS-DEACMS micelles displayed similar root growth inhibition compared to free 2,4-D, and the root length and fresh weight was reduced to around $23 \%$ and $50 \%$ compared to the control plant with deionized water, demonstrating the good herbicidal bioactivity of the 2,4-D-loaded CMCS-DEACMS micelles.

Wheat was selected as a model monocot plant to evaluate the safety of 2,4-D loaded micelles, since 2,4-D is safe for monocot plants under the recommended dosage. At the maximum 2,4-D dosage recommended for field application $(2.5 \mathrm{~kg} / \mathrm{ha})$, both the 2,4-D-containing micelles and free 2,4-D applied post-emergency had no harmful effect on the plant height and free weight (Figure 7). Earlier reports have also shown that 2,4-D nanocarriers do not affect the growth of nontarget plants (wheat or Zea mays) $[40,48]$. Therefore, the prepared CMCS-DEACMS micelles can be recognized as desirable herbicide nanocarriers for nontarget monocot plants.
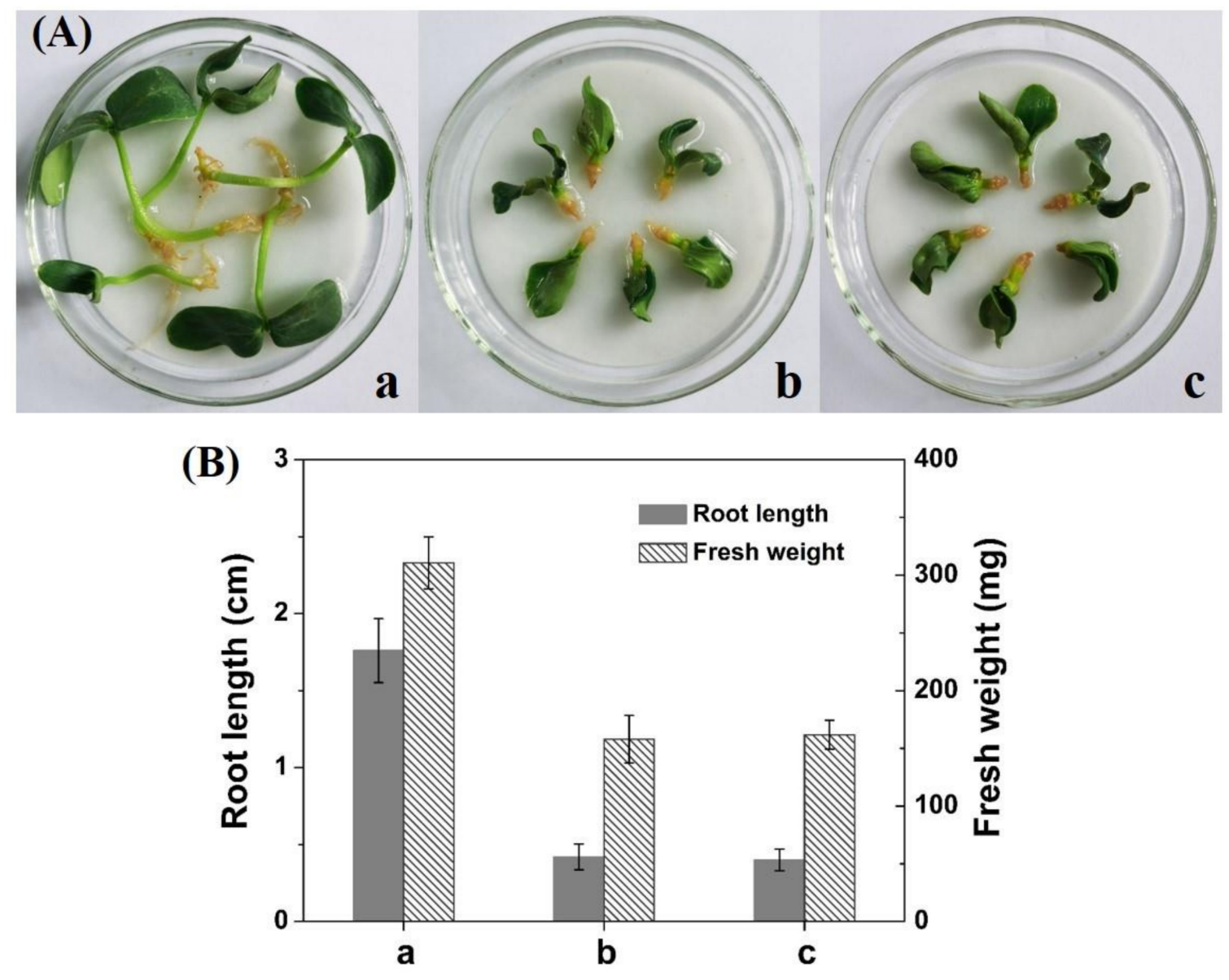

Figure 6. Bioactivity for target plant cucumber. (A) Photographs and (B) root height and fresh weight of cucumber for (a) control with deionized water, (b) free 2,4-D and (c) 2,4-D-loaded CMCS-DEACMS micelles. 

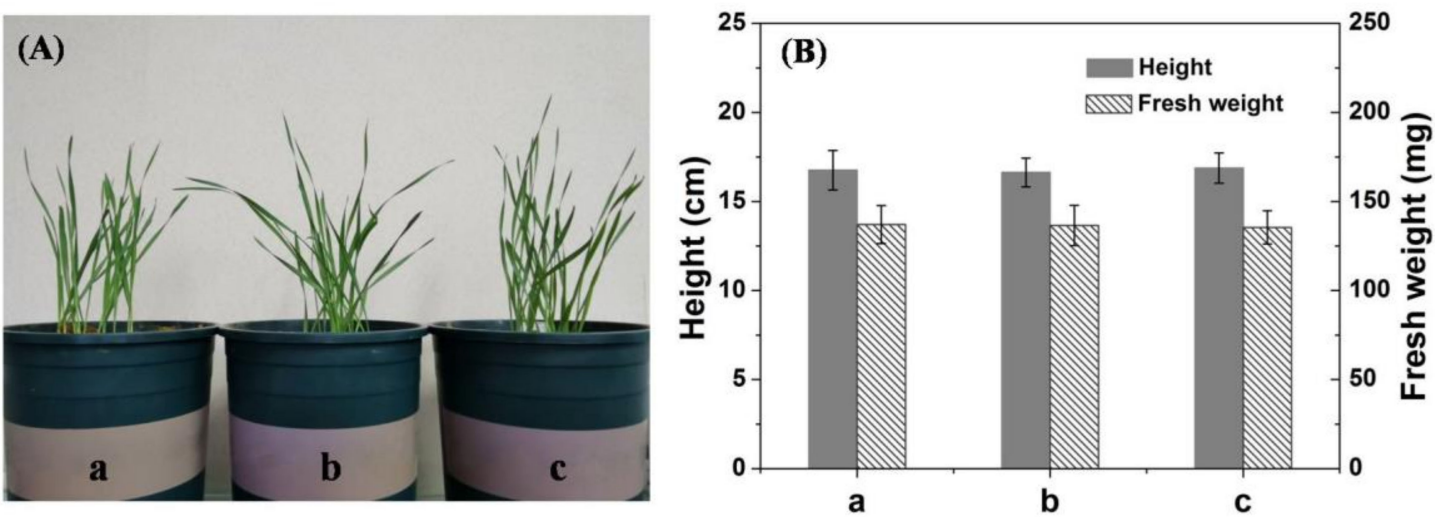

Figure 7. Bioactivity for nontarget plant wheat. (A) Photographs and (B) height and fresh weight of wheat for (a) control with deionized water, (b) free 2,4-D and (c) 2,4-D-loaded CMCS-DEACMS micelles.

\section{Conclusions}

A novel light-responsive amphiphilic CMCS-DEACMS nanocarrier for pesticide was successfully prepared by introducing hydrophobic and photolabile coumarin groups onto the main chain of hydrophilic CMCS. The chemical structures were characterized by FTIR and NMR. The amphiphilic CMCS-DEACMS can be self-assembled into spherical micelles in aqueous solution through the hydrophobic interaction between the DEACMS groups. The destabilization of the micelles in aqueous solution under simulated sunlight irradiation leads to accelerated 2,4-D release from the micelles. Further, good bioactivity was observed on the target plant with no impact on the nontarget plant. Hence, this new type of light-responsive CMCS-DEACMS micelle as a nanocarrier holds great potential for smart pesticide delivery in the agricultural industry.

Supplementary Materials: The supplementary materials are available online at http://www.mdpi.com/2073-4360/ 12/10/2268/s1.

Author Contributions: Investigation and analysis, S.F.; cooperation with synthesis and characterization, J.W., N.K., W.Y. and Q.C.; conceptualization and writing — original draft preparation, L.Z.; writing-review and editing, H.X. All authors have read and agreed to the published version of the manuscript.

Funding: This work was financially supported by the National Natural Science Foundation of China (51803038); Science and Technology Department of Guizhou Province \& Guizhou University Joint Fund ([2017]7249); National Innovation and Entrepreneurship training Program for College Students (201810657005); Academic New Seedling Cultivation and Innovative Exploration Special Project of Guizhou University ([2017]5788) and Talent Introduction Program of Guizhou University ([2017]08); The Science and Technology Department of Guizhou Province (Platform \& Talents Grant No. [2016]5652 and [2019]5607).

Conflicts of Interest: The authors declare no conflict of interest.

\section{References}

1. Chen, C.; Zhang, G.; Dai, Z.; Xiang, Y.; Liu, B.; Bian, P.; Zheng, K.; Wu, Z.; Cai, D. Fabrication of light-responsively controlled-release herbicide using a nanocomposite. Chem. Eng. J. 2018, 349, 101-110. [CrossRef]

2. Xiang, Y.; Zhang, G.; Chi, Y.; Cai, D.; Wu, Z. Fabrication of a controllable nanopesticide system with magnetic collectability. Chem. Eng. J. 2017, 328, 320-330. [CrossRef]

3. Kumar, S.; Nehra, M.; Dilbaghi, N.; Marrazza, G.; Hassan, A.A.; Kim, K.H. Nano-based smart pesticide formulations: Emerging opportunities for agriculture. J. Control. Release 2019, 294, 131-153. [CrossRef] [PubMed]

4. Zhao, X.; Cui, H.; Wang, Y.; Sun, C.; Cui, B.; Zeng, Z. Development strategies and prospects of nano-based smart pesticide formulation. J. Agric. Food Chem. 2018, 66, 6504-6512. [CrossRef]

5. Liu, Z.; Qie, R.; Li, W.; Hong, N.; Li, Y.; Li, C.; Wang, R.; Shi, Y.; Guo, X.; Jia, X. Preparation of avermectin microcapsules with anti-photodegradation and slow-release by the assembly of lignin derivatives. New J. Chem. 2017, 41, 3190-3195. [CrossRef] 
6. Chauhan, N.; Dilbaghi, N.; Gopal, M.; Kumar, R.; Kim, K.-H.; Kumar, S. Development of chitosan nanocapsules for the controlled release of hexaconazole. Int. J. Biol. Macromol. 2017, 97, 616-624. [CrossRef]

7. Grillo, R.; Pereira, A.E.S.; Nishisaka, C.S.; De Lima, R.; Oehlke, K.; Greiner, R.; Fraceto, L.F. Chitosan/tripolyphosphate nanoparticles loaded with paraquat herbicide: An environmentally safer alternative for weed control. J. Hazard. Mater. 2014, 278, 163-171. [CrossRef]

8. Dailey, O.D. Volatilization of alachlor from polymeric formulations. J. Agric. Food Chem. 2004, 52, 6742-6746. [CrossRef]

9. Fernández-Pérez, M.; Villafranca-Sánchez, M.; González-Pradas, E.; Flores-Céspedes, F. Controlled release of diuron from an alginate-bentonite formulation: Water release kinetics and soil mobility study. J. Agric. Food Chem. 1999, 47, 791-798. [CrossRef]

10. Lao, S.B.; Zhang, Z.X.; Xu, H.H.; Jiang, G.B. Novel amphiphilic chitosan derivatives: Synthesis, characterization and micellar solubilization of rotenone. Carbohydr. Polym. 2010, 82, 1136-1142. [CrossRef]

11. Campos, E.V.R.; De Oliveira, J.L.; Fraceto, L.F.; Singh, B. Polysaccharides as safer release systems for agrochemicals. Agron. Sustain. Dev. 2015, 35, 47-66. [CrossRef]

12. Wang, X.; Zhao, J. Encapsulation of the herbicide picloram by using polyelectrolyte biopolymers as layer-by-layer materials. J. Agric. Food Chem. 2013, 61, 3789-3796. [CrossRef] [PubMed]

13. Guo, M.; Zhang, W.; Ding, G.; Guo, D.; Zhu, J.; Wang, B.; Punyapitak, D.; Cao, Y. Preparation and characterization of enzyme-responsive emamectin benzoate microcapsules based on a copolymer matrix of silica-epichlorohydrin-carboxymethylcellulose. RSC Adv. 2015, 5, 93170-93179. [CrossRef]

14. Atta, S.; Paul, A.; Banerjee, R.; Bera, M.; Ikbal, M.; Dhara, D.; Singh, N.D.P. Photoresponsive polymers based on a coumarin moiety for the controlled release of pesticide 2,4-D. RSC Adv. 2015, 5, 99968-99975. [CrossRef]

15. Kumar, S.; Chauhan, N.; Gopal, M.; Kumar, R.; Dilbaghi, N. Development and evaluation of alginate-chitosan nanocapsules for controlled release of acetamiprid. Int. J. Biol. Macromol. 2015, 81, 631-637. [CrossRef]

16. Binder, C.R.; García-Santos, G.; Andreoli, R.; Diaz, J.; Feola, G.; Wittensoeldner, M.; Yang, J. Simulating human and environmental exposure from hand-held knapsack pesticide application: Be-wetspa-pest, an integrative, spatially explicit modeling approach. J. Agric. Food Chem. 2016, 64, 3999-4008. [CrossRef]

17. Liu, B.; Chen, C.; Wang, R.; Dong, S.; Li, J.; Zhang, G.; Cai, D.; Zhai, S.; Wu, Z. Near-infrared light-responsively controlled-release herbicide using biochar as a photothermal agent. ACS Sustain. Chem. Eng. 2019, 7, 14924-14932. [CrossRef]

18. Camara, M.C.; Campos, E.V.R.; Monteiro, R.A.; Do Espirito Santo Pereira, A.; De Freitas Proença, P.L.; Fraceto, L.F. Development of stimuli-responsive nano-based pesticides: Emerging opportunities for agriculture. J. Nanobiotechnol. 2019, 17, 100. [CrossRef]

19. Hou, X.B.; Pan, Y.F.; Xiao, H.N.; Liu, J. Controlled release of agrochemicals using $\mathrm{pH}$ and redox dual-responsive cellulose nanogels. J. Agric. Food Chem. 2019, 67, 6700-6707. [CrossRef]

20. Sarkar, D.J.; Singh, A. Base triggered release of insecticide from bentonite reinforced citric acid crosslinked carboxymethyl cellulose hydrogel composites. Carbohydr. Polym. 2017, 156, 303-311. [CrossRef]

21. Mattos, B.D.; Tardy, B.L.; Pezhman, M.; Kämäräinen, T.; Linder, M.; Schreiner, W.H.; Magalhães, W.L.E.; Rojas, O.J. Controlled biocide release from hierarchically-structured biogenic silica: Surface chemistry to tune release rate and responsiveness. Sci. Rep. 2018, 8, 5555. [CrossRef] [PubMed]

22. Ye, Z.; Guo, J.; Wu, D.; Tan, M.; Xiong, X.; Yin, Y.; He, G. Photo-responsive shell cross-linked micelles based on carboxymethyl chitosan and their application in controlled release of pesticide. Carbohydr. Polym. 2015, 132, 520-528. [CrossRef] [PubMed]

23. Meng, L.; Huang, W.; Wang, D.; Huang, X.; Zhu, X.; Yan, D. Chitosan-based nanocarriers with pH and light dual response for anticancer drug delivery. Biomacromolecules 2013, 14, 2601-2610. [CrossRef] [PubMed]

24. Fomina, N.; Mcfearin, C.; Sermsakdi, M.; Edigin, O.; Almutairi, A. UV and near-IR triggered release from polymeric nanoparticles. J. Am. Chem. Soc. 2010, 132, 9540-9542. [CrossRef]

25. Murase, N.; Mukawa, T.; Sunayama, H.; Takeuchi, T. Molecularly imprinted polymers bearing spiropyran-based photoresponsive binding sites capable of photo-triggered switching for molecular recognition activity. J. Polym. Sci. Part B Polym. Phys. 2016, 54, 1637-1644. [CrossRef]

26. Beauté, L.; Mcclenaghan, N.; Lecommandoux, S. Photo-triggered polymer nanomedicines: From molecular mechanisms to therapeutic applications. Adv. Drug Deliv. Rev. 2019, 138, 148-166. [CrossRef] 
27. Gandioso, A.; Contreras, S.; Melnyk, I.; Oliva, J.; Nonell, S.; Velasco, D.; García-Amorós, J.; Marchán, V. Development of green/red-absorbing chromophores based on a coumarin scaffold that are useful as caging groups. J. Org. Chem. 2017, 82, 5398-5408. [CrossRef]

28. Atta, S.; Jana, A.; Ananthakirshnan, R.; Narayana Dhuleep, P.S. Fluorescent caged compounds of 2,4-dichlorophenoxyacetic acid (2,4-D): Photorelease technology for controlled release of 2,4-D. J. Agric. Food Chem. 2010, 58, 11844-11851. [CrossRef]

29. Klán, P.; Šolomek, T.; Bochet, C.G.; Blanc, A.; Givens, R.; Rubina, M.; Popik, V.; Kostikov, A.; Wirz, J. Photoremovable protecting groups in chemistry and biology: Reaction mechanisms and efficacy. Chem. Rev. 2013, 113, 119-191. [CrossRef]

30. Iturmendi, A.; Theis, S.; Maderegger, D.; Monkowius, U.; Teasdale, I. Coumarin-caged polyphosphazenes with a visible-light driven on-demand degradation. Macromol. Rapid Commun. 2018, 39, 1800377. [CrossRef]

31. Xu, Z.P.; Gao, Z.H.; Shao, X.S. Light-triggered release of insecticidally active spirotetramat-enol. Chin. Chem. Lett. 2018, 29, 1648-1650. [CrossRef]

32. Pang, Y.; Li, X.; Wang, S.; Qiu, X.; Yang, D.; Lou, H. Lignin-polyurea microcapsules with anti-photolysis and sustained-release performances synthesized via pickering emulsion template. React. Funct. Polym. 2018, 123, 115-121. [CrossRef]

33. Kamari, A.; Aljafree, N.F.A.; Yusoff, S.N.M. N,N-dimethylhexadecyl carboxymethyl chitosan as a potential carrier agent for rotenone. Int. J. Biol. Macromol. 2016, 88, 263-272. [CrossRef] [PubMed]

34. Li, Y.; Zhou, M.; Pang, Y.; Qiu, X. Lignin-based microsphere: Preparation and performance on encapsulating the pesticide avermectin. ACS Sustain. Chem. Eng. 2017, 5, 3321-3328. [CrossRef]

35. Li, J.; Li, Y.; Dong, H. Controlled release of herbicide acetochlor from clay/carboxylmethylcellulose gel formulations. J. Agric. Food Chem. 2008, 56, 1336-1342. [CrossRef] [PubMed]

36. Gabriel, J.D.; Tiera, M.J.; Tiera, V.A.D. Synthesis, characterization, and antifungal activities of amphiphilic derivatives of diethylaminoethyl citosan against Aspergillus flavus. J. Agric. Food Chem. 2015, 63, 5725-5731. [CrossRef] [PubMed]

37. Katiyar, D.; Hemantaranjan, A.; Singh, B. Chitosan as a promising natural compound to enhance potential physiological responses in plant: A review. Indian J. Plant Physiol. 2015, 20, 1-9. [CrossRef]

38. Mujtaba, M.; Khawar, K.M.; Camara, M.C.; Carvalho, L.B.; Fraceto, L.F.; Morsi, R.E.; Elsabee, M.Z.; Kaya, M.; Labidi, J.; Ullah, H.; et al. Chitosan-based delivery systems for plants: A brief overview of recent advances and future directions. Int. J. Biol. Macromol. 2020, 154, 683-697. [CrossRef]

39. Zhao, M.; Zhou, H.; Chen, L.; Hao, L.; Chen, H.; Zhou, X. Carboxymethyl chitosan grafted trisiloxane surfactant nanoparticles with $\mathrm{pH}$ sensitivity for sustained release of pesticide. Carbohydr. Polym. 2020, 243, 116433. [CrossRef]

40. Abigail M, E.A.; Samuel S, M.; Chidambaram, R. Application of rice husk nanosorbents containing 2,4-dichlorophenoxyacetic acid herbicide to control weeds and reduce leaching from soil. J. Taiwan Inst. Chem. Eng. 2016, 63, 318-326. [CrossRef]

41. Wu, Y.G.; Chan, W.L.; Szeto, Y.S. Preparation of O-carboxymethyl chitosans and their effect on color yield of acid dyes on silk. J. Appl. Polym. Sci. 2003, 90, 2500-2502. [CrossRef]

42. Huang, Q.; Bao, C.; Ji, W.; Wang, Q.; Zhu, L. Photocleavable coumarin crosslinkers based polystyrene microgels: Phototriggered swelling and release. J. Mater. Chem. 2012, 22, 18275-18282. [CrossRef]

43. Jena, S.K.; Sangamwar, A.T. Polymeric micelles of amphiphilic graft copolymer of $\alpha$-tocopherol succinate-g-carboxymethyl chitosan for tamoxifen delivery: Synthesis, characterization and in vivo pharmacokinetic study. Carbohydr. Polym. 2016, 151, 1162-1174. [CrossRef] [PubMed]

44. Wang, X.; Guo, Y.; Qiu, L.; Wang, X.; Li, T.; Han, L.; Ouyang, H.; Xu, W.; Chu, K. Preparation and evaluation of carboxymethyl chitosan-rhein polymeric micelles with synergistic antitumor effect for oral delivery of paclitaxel. Carbohydr. Polym. 2019, 206, 121-131. [CrossRef] [PubMed]

45. Wang, D.; Tan, J.; Kang, H.; Ma, L.; Jin, X.; Liu, R.; Huang, Y. Synthesis, self-assembly and drug release behaviors of $\mathrm{pH}$-responsive copolymers ethyl cellulose-graft-PDEAEMA through ATRP. Carbohydr. Polym. 2011, 84, 195-202. [CrossRef]

46. Zhong, H.Q.; Liu, C.C.; Ge, W.J.; Sun, R.C.; Huang, F.; Wang, X.H. Self-assembled conjugated polymer/chitosan-graft-oleic acid micelles for fast visible detection of aliphatic biogenic amines by "turn-on" FRET. ACS App. Mater. Interfaces 2017, 9, 22875-22884. [CrossRef] 
47. Shen, F.; Zhong, H.; Ge, W.; Ren, J.; Wang, X. Quercetin/chitosan-graft-alpha lipoic acid micelles: A versatile antioxidant water dispersion with high stability. Carbohydr. Polym. 2020, 234, 115927. [CrossRef]

48. Cao, L.D.; Zhou, Z.L.; Niu, S.J.; Cao, C.; Li, X.H.; Shan, Y.P.; Huang, Q.L. Positive-charge functionalized mesoporous silica nanoparticles as nanocarriers for controlled 2,4-dichlorophenoxy acetic acid sodium salt release. J. Agric. Food Chem. 2018, 66, 6594-6603. [CrossRef]

49. Hermosín, M.C.; Celis, R.; Facenda, G.; Carrizosa, M.J.; Ortega-Calvo, J.J.; Cornejo, J. Bioavailability of the herbicide 2,4-D formulated with organoclays. Soil Biol. Biochem. 2006, 38, 2117-2124. [CrossRef]

50. Rege, P.D.; Tian, Y.; Corey, E.J. Studies of new indole alkaloid coupling methods for the synthesis of haplophytine. Org. Lett. 2006, 8, 3117-3120. [CrossRef]

51. Yan, F.; Chen, L.; Tang, Q.; Wang, R. Synthesis and characterization of a photocleavable cross-linker and its application on tunable surface modification and protein photodelivery. Bioconj. Chem. 2004, 15, 1030-1036. [CrossRef] [PubMed]

52. Jiang, Z.; Han, B.; Li, H.; Yang, Y.; Liu, W. Carboxymethyl chitosan represses tumor angiogenesis in vitro and in vivo. Carbohydr. Polym. 2015, 129, 1-8. [CrossRef] [PubMed]

53. Cao, J.; Zheng, H.; Hu, R.; Liao, J.; Fei, Z.; Wei, X.; Xiong, X.; Zhang, F.; Zheng, H.; Li, D. pH-Responsive nanoparticles based on covalently grafted conjugates of carboxymethyl chitosan and daunorubicin for the delivery of anti-cancer drugs. J. Biomed. Nanotechnol. 2017, 13, 1647-1659. [CrossRef] [PubMed]

54. Du, J.; Hsieh, Y.-L. Nanofibrous membranes from aqueous electrospinning of carboxymethyl chitosan. Nanotechnology 2008, 19, 125707. [CrossRef] [PubMed]

55. Rinaudo, M.; Dung, P.; Gey, C.; Milas, M. Substituent distribution on O, N-carboxymethylchitosans by $1 \mathrm{H}$ and 13C NMR. Int. J. Biol. Macromol. 1992, 14, 122-128. [CrossRef]

56. Du, Y.-Z.; Wang, L.; Yuan, H.; Wei, X.-H.; Hu, F.-Q. Preparation and characteristics of linoleic acid-grafted chitosan oligosaccharide micelles as a carrier for doxorubicin. Colloids Surf. B 2009, 69, 257-263. [CrossRef]

57. Suzuki, A.Z.; Watanabe, T.; Kawamoto, M.; Nishiyama, K.; Yamashita, H.; Ishii, M.; Iwamura, M.; Furuta, T. Coumarin-4-ylmethoxycarbonyls as phototriggers for alcohols and phenols. Org. Lett. 2003, 5, 4867. [CrossRef]

58. Roche, A.; Terriac, E.; Tejedor, R.M.; Oriol, L.; Del Campo, A.; Piñol, M. Supramolecular block copolymers as novel UV and NIR responsive nanocarriers based on a photolabile coumarin unit. Eur. Polym. J. 2020, 126, 109561. [CrossRef]

59. Li, H.B.; Chen, C.M.; An, Q.; Huo, G.Y.; Run, M.T. Photo-responsive nanoparticles for beta-lapachone delivery in vitro. Chin. Chem. Lett. 2018, 29, 1347-1349. [CrossRef]

60. Zhang, Y.F.; Chen, W.; Jing, M.M.; Liu, S.Z.; Feng, J.T.; Wu, H.; Zhou, Y.W.; Zhang, X.; Ma, Z.Q. Self-assembled mixed micelle loaded with natural pyrethrins as an intelligent nano-insecticide with a novel temperature-responsive release mode. Chem. Eng. J. 2019, 361, 1381-1391. [CrossRef]

Publisher's Note: MDPI stays neutral with regard to jurisdictional claims in published maps and institutional affiliations.

(C) 2020 by the authors. Licensee MDPI, Basel, Switzerland. This article is an open access article distributed under the terms and conditions of the Creative Commons Attribution (CC BY) license (http://creativecommons.org/licenses/by/4.0/). 